\title{
Bioefficacy of cow urine based eco-friendly formulations against Spilarctia obliqua (Walker)
}

\section{Geetanjaly* and Ruchira Tiwari}

Department of Entomology, G.B. Pant University of Agriculture \& Technology, Pantnagar- 263145, U.S. Nagar (Uttarakhand), INDIA

*Corresponding author. E-mail: ruchis03@rediffmail.com

Received: June 24, 2014; Revised received: September 6, 2014; Accepted: November 21, 2014

\begin{abstract}
The laboratory studies were conducted to assess the bio-efficacy of cow urine and jatropha seed extracts prepared in water and cow urine $(@ 5 \%$ and @10\% against different stages of Spilarctia obliqua. The cent per- cent mortality of neonate larvae was observed in jatropha seed water extract @10\% followed by significantly less larval survival in cow urine @10\% (13.35\%), jatropha seed cow urine extract @10\% $(16.64 \%)$ in comparison to untreated control (93.32\%).Similarly cent per cent larval mortality of 7 days old larvae was observed in JSWE @ 10\% and JSCUE @10\% with significantly less growth index in JSCUE 5\% (0.66), JSWE@5\%( 0.67), CU @ 10\% (0.88) and CU @5\% ( 0.99) with 2.23 growth index in untreated control. For 14 days old larvae the mean leaf area consumed and larval weight was observed significantly very less in JSWE@10\% with cent percent larval mortality followed by JSCUE@10\% and cow urine treatments. Similarly, regarding antifeedant activity of eco-friendly formulations according to the calculated preference indices, the strong antifeedant action was showed by JSWE@10\% (0.50) followed by JSCUE@10\% (0.55)and JSWE@5\% (0.60) showed moderately antifeedant action with slight antifeedant action in JSCUE@5\% (0.81) and cow urine @10\% ( 0.82) and CU@5\%(0.85). These observations clearly demonstrated the efficacy of cow urine based eco-friendly formulations against $S$. obliqua under laboratory conditions which indicated the potential of cow urine based formulations which are eco-friendly, easily prepared and low cost organic approach for sustainable agriculture.
\end{abstract}

Keywords: Antifeedant, Cow urine, Jatropha seed, S. obliqua

\section{INTRODUCTION}

Bihar hairy caterpillar, Spilarctia obliqua (Walker) is a polyphagus pest, feeding on pulses, sesamum, linseed, cotton, jute, sorghum, groundnut and some vegetables. Hairy caterpillar is reported to be a major pest of soybean (Garg and Sachan ,1992). During the early instars, the caterpillars feed gregariously on the leaves and then disperse. In severe infestations, plants may be completely denuded (Srivastava, 1993).

The use of conventional insecticides has raised some concern about their threat to the environment and development of insecticide resistance in insects (Huang et al., 1998). In recent years, alternative to synthetic pesticides for effective pest control in different agro-system have been investigated. Amongst them, plant derived products and cow urine are proved to be eco-friendly, residue free, bio degradable and cost-effective. Therefore, utilization of these products came in attention into the developing and less developed countries (Gahukar, 2014).

There is an imperative need for the development of safer, alternative crop protectant such as botanical Insecticides and antifeedants. Plants are rich sources of natural substances that can be utilized in the development of environmentally safe methods for insect control (Sadek, 2003). Several workers reported the use of plant materials and cow urine for the control of insect pests of field crops (Patel and Gajjer, 2001; Dubey et al., 2004 Gupta, 2005; Sharma et al., 2009; Chand and Tiwari , 2010; Geetanjaly and Tiwari, 2013). Keeping this in view, the present study was designed to assess the effect of cow urine based formulations alone and jatropha seed extracts in water and cow urine on feeding preference and growth and development of $S$. obliqua for its eco-friendly management.

\section{MATERIALS AND METHODS}

The present study was carried out in the Department of Entomology, College of Agriculture, GB Pant University of Agriculture and Technology, Pant Nagar, Uttarakhand.

Culture of the test insect: The culture of S. obliqua was raised in glass jars on leaves of castor, Ricinus communis (Linn.) The nucleus culture of the test insect larvae was collected from University premises and brought to the laboratory, were reared on fresh castor leaves till pupation and healthy pupae were 
procured for the next generation. The culture was maintained at $27^{\circ} \mathrm{C}$ and $70 \pm 5 \% \mathrm{RH}$. The adults obtained from above culture were released in separate glass jars $\left(21 \times 15 \mathrm{~cm}^{2}\right)$ the walls of which were lined with white paper for egg laying. White paper strips were also kept in the jars for egg laying and muslin cloth and strips were checked daily for egg laying and eggs were removed and placed in separate jars on fresh succulent castor leaves for hatching. The neonate larvae were reared on fresh castor leaves to maintain the test culture of $S$. obliqua. In adulthood, the culture had been covered with muslin cloth and continuously supplemented with $10 \%$ honey solution to adults as a food. To get homogenous population one generation passed larvae were used for the experiment. (Panwar and Chibber, 2006)

Extraction of bioactive compounds: The jatropha seed were collected from the University campus and nearby areas of Pantnagar, whereas, cow urine was collected from desi breed cow. The seed were first washed with water to remove the dust particles or foreign matter, dried in shade just to remove water intact with seed during wash. To prepare @5\% and @ $10 \%$ concentrations of jatropha seed extract in water and cow urine, separately, 50 and 100 grams of jatropha seed weighed separately by using a top balance, macerated in the electrical grinder and dipped in $1000 \mathrm{ml}$ of water and cow urine separately in the containers and were kept for fermentation for $24 \mathrm{hrs}$ and then filter by using muslin cloth. Similar concentrations were taken for cow urine when used alone.

Bioassay: The growth and development of different larval stages of $S$. obliqua on different treated leaf discs was evaluated by using no-choice test method as suggested by (Singh et al., 1995). Fresh castor leaf discs $\left(4 \times 4 \mathrm{~cm}^{2}\right)$ were treated with cow urine and plant extracts, separately, with the help of atomizer and placed in tilted orientation under ceiling fan air dried at room temperature in the laboratory to evaporate water from the leaf and kept in a pertidishes lined with moist filter paper to maintain the humidity treatment wise separately. Thereafter, 10 larvae / replication of different stages of $S$. obliqua, separately were released into each petri dish (90mm dia.) containing treated leaf disc and allowed to feed till pupation. Each treatment was replicated thrice. In control, the leaf discs were dipped in distilled water and dried before being given to larvae. Observations were recorded on the different growth parameters such as larval weight, larval survival, pupal period pupal survival, per cent adult emergence and growth index using following formula given by (Pant, 1956):

Growth index $=$ Percent adult emergence $/$ Total developmental period

Feeding preference: Similar procedure as above was followed with single 10 days old larvae starved for 6 hrs with known weight were subjected to bioassay using treated leaf discs separately in triplicates. The area of leaf consumed by the larvae on treated and untreated leaves was recorded till pupation at the interval of 24 hours with the help of graph paper and the larval, pupal and adult weight was taken simultaneously. (Singh and Pant, 1980)

The percent feeding in each treatment over control was worked out using the following formula:

Percent feeding = Initial area given for feeding - leaf area left after feeding $\times 100 /$ Initial area given for feeding

Antifeedant activity was compared using the following formula:

(\%) Antifeedant $=$ Area eaten in untreated leaf-Area eaten in treated leaves $\times 100$ /Area eaten in untreated leaf

$\%$ Feeding inhibition (FI) was calculated following (Pande and Shrivastav 2003).

$\mathrm{FI}=(\mathrm{C}-\mathrm{T}) /(\mathrm{C}+\mathrm{T}) \times 100$

Where, $\mathrm{C}=$ Consumption of control leaves, $\mathrm{T}=$ Consumption of treated leaves, Preference index was calculated according to Kogan and Geoden, (1970)

$\mathrm{C}=2 \mathrm{~A} / \mathrm{M}+\mathrm{A}$

Where $\mathrm{C}=$ Preference index, $\mathrm{A}=$ area eaten on the treated leaf, $\mathrm{M}=$ area eaten on the untreated leaf

The Antifeedant activity of each plant extracts was worked out on the basis of preference indices (C-values) according to the following scale as given by (Sharma and Bisht, 2008)

\begin{tabular}{ll}
\hline C-value & \multicolumn{1}{c}{ Class } \\
\hline $0.1-0.25$ & Extremely antifeedant \\
$0.26-0.50$ & Strong antifeedant \\
$0.51-0.75$ & Moderately antifeedant \\
$0.76-0.99$ & Slightly antifeedant \\
$>1$ & Preferred plant extract \\
\hline
\end{tabular}

Data subjected to complete randomized design (CRD) (two factorial) after suitable transformations using programme STPR3

\section{RESULTS AND DISCUSSION}

Effect of Jatropha seed extracts on growth and development of 0-24 hr) old larvae of $S$. oblique: The data presented in Table1 clearly demonstrated the efficacy of jatropha seed extracts against neonate larvae of $S$. obliqua. As cent per-cent larval mortality was observed in JSWE (Jatropha seed water extract) @ 10 per cent within 3-4 days of exposure whereas in other treatments the larval survival was ranged from in $\mathrm{CU}$ (cow urine) @ 10\%(13.35\%), in JSWE @ 5\% ( $26.66 \%$ ) was very less as compared to $93.32 \%$ larval survival in untreated control. The larval period was extended in treated castor leaf discs to the extent of $25.45-27.40$ days with extended pupal period $(9.50$ -10.24 days) and significantly very less pupation were recorded in jatropha seed extracts treated caster leaves (13.33- 16.65\%), adult emergence (10.02-13.35\%) and growth indices values (0.285-0.364) in comparison to untreated control, where average larval 
Table 1. Effects of Jatropha seed extracts on growth and developmental behavior of neonate larvae (0-24hrs) of S. obliqua.

\begin{tabular}{|c|c|c|c|c|c|c|c|}
\hline Treatment & Conc. & $\begin{array}{l}\text { \% larval } \\
\text { survival }\end{array}$ & $\begin{array}{l}\text { Larval period } \\
\text { (days) }\end{array}$ & $\begin{array}{c}\text { Pupation } \\
(\%)\end{array}$ & $\begin{array}{l}\text { Pupal } \\
\text { period } \\
\text { (days) } \\
\end{array}$ & $\begin{array}{c}\text { Adult } \\
\text { emergence } \\
(\%) \\
\end{array}$ & $\begin{array}{c}\text { Growth } \\
\text { index (G.I.) }\end{array}$ \\
\hline JSWE & 5 & $\begin{array}{c}26.66 \\
(31.08)\end{array}$ & $\begin{array}{c}25.45 \\
(30.31)\end{array}$ & $\begin{array}{c}13.33 \\
(21.42)\end{array}$ & $\begin{array}{c}9.57 \\
(18.02)\end{array}$ & $\begin{array}{c}0.00 \\
(0.00)\end{array}$ & 0.00 \\
\hline JSWE & 10 & $\begin{array}{c}0.00 \\
(0.00)\end{array}$ & $\begin{array}{c}0.00 \\
(0.00)\end{array}$ & $\begin{array}{c}0.00 \\
(0.00)\end{array}$ & $\begin{array}{c}0.00 \\
(0.00)\end{array}$ & $\begin{array}{c}0.00 \\
(0.00)\end{array}$ & 0.00 \\
\hline JSCUE & 5 & $\begin{array}{c}33.34 \\
(35.27)\end{array}$ & $\begin{array}{c}26.47 \\
(30.96)\end{array}$ & $\begin{array}{c}16.65 \\
(24.08)\end{array}$ & $\begin{array}{c}10.24 \\
(18.66)\end{array}$ & $\begin{array}{c}13.35 \\
(21.44)\end{array}$ & 0.364 \\
\hline JSCUE & 10 & $\begin{array}{c}16.64 \\
(24.08)\end{array}$ & $\begin{array}{c}27.40 \\
(31.57)\end{array}$ & $\begin{array}{c}0.00 \\
(0.00)\end{array}$ & $\begin{array}{c}0.00 \\
(0.00)\end{array}$ & $\begin{array}{c}0.00 \\
(0.00)\end{array}$ & 0.00 \\
\hline $\mathrm{CU}$ & 5 & $\begin{array}{c}26.52 \\
(30.99)\end{array}$ & $\begin{array}{c}25.54 \\
(30.35)\end{array}$ & $\begin{array}{c}13.35 \\
(21.43)\end{array}$ & $\begin{array}{c}9.50 \\
(17.95)\end{array}$ & $\begin{array}{c}10.02 \\
(1.846)\end{array}$ & 0.285 \\
\hline $\mathrm{CU}$ & 10 & $\begin{array}{c}13.35 \\
(21.43)\end{array}$ & $\begin{array}{c}26.40 \\
(30.92)\end{array}$ & $\begin{array}{c}0.00 \\
(0.00)\end{array}$ & $\begin{array}{c}0.00 \\
(0.00)\end{array}$ & $\begin{array}{c}0.00 \\
(0.00)\end{array}$ & 0.00 \\
\hline CONTROL & - & $\begin{array}{c}93.32 \\
(75.02)\end{array}$ & $\begin{array}{c}20.27 \\
(26.76)\end{array}$ & $\begin{array}{c}93.34 \\
(75.04)\end{array}$ & $\begin{array}{c}9.17 \\
(17.63)\end{array}$ & $\begin{array}{c}90.02 \\
(71.58)\end{array}$ & 3.050 \\
\hline SEm \pm & & $\begin{array}{c}0.05 \\
(0.03)\end{array}$ & $\begin{array}{c}0.00 \\
(0.08)\end{array}$ & $\begin{array}{c}0.00 \\
(0.008)\end{array}$ & $\begin{array}{c}0.11 \\
(0.10)\end{array}$ & $\begin{array}{c}0.00 \\
(0.01)\end{array}$ & \\
\hline $\mathrm{CD}$ at $5 \%$ & & $\begin{array}{c}0.16 \\
(0.11)\end{array}$ & $\begin{array}{c}0.42 \\
(0.27)\end{array}$ & $\begin{array}{c}0.02 \\
(0.02)\end{array}$ & $\begin{array}{c}0.32 \\
(0.03)\end{array}$ & $\begin{array}{c}0.02 \\
(0.03)\end{array}$ & \\
\hline $\mathrm{CV}$ & & $\begin{array}{c}0.31 \\
(0.19)\end{array}$ & $\begin{array}{c}1.10 \\
(0.60)\end{array}$ & $\begin{array}{c}0.06 \\
(0.07)\end{array}$ & $\begin{array}{c}3.30 \\
(1.71)\end{array}$ & $\begin{array}{c}0.10 \\
(0.12)\end{array}$ & \\
\hline
\end{tabular}

JSWE- Jatropha Seed water extract, JSCUE- Jatropa seed cow urine extract, CU- Cow urine

period, per-cent pupation, adult emergence and growth index were 20.27 days, 93.34, 90.02, 3.050 respectively. There results clearly showed that higher antifeedant and growth regulatory effect of jatropha seed extracts and cow urine against neonate larvae and the freshly emerged larave were highly sensitive to the plant extracts as evidence by higher larval and pupal mortality with adult deformities.

Effect of Jatropha seed extracts on growth and development of 7 days old larvae of $\boldsymbol{S}$. obliqua: The results obtained during the present studies on the effect of jatropha extracts on the growth and development of 7 days old larvae of $S$. obliqua is given in table- 2 . The jatropha seed extracts prepared in water and cow urine again found very effective with cent per cent larval mortality after feeding on the treated leaves for 5-6 days with significantly less larval survival (16.65\%) in JSWE@ @ 10\% and CU @ 10\% in comparison to other treatments per cent larval survival ranging from 16.65-50.24\% as compared to $99.98 \%$ larval survival in untreated control. The average larval and pupal period were extended on the treated castor leaf discs to the extent of 13.33-16.65 days and 18.4618.99 days respectively with reduction in per cent pupation (21.42-39.35\%), adult emergence (21.42$35.27 \%)$ and growth indices values $(0.66-0.99)$, In comparison the untreated castor leaf discs where the larval and pupal periods were significantly 13.0 days and 17.69 days, respectively, percent pupation ( $75.04 \%)$ and adult emergence $(68.59 \%)$ significantly higher with higher growth index value (2.23).
The above findings showed that the larvae of S. obliqua were more sensitive to jatropha seed extracts and Cow urine at 10 percent concentration than the 5 percent concentration. And higher larval mortality was observed with higher pupal and adult deformities and lower growth indices values at higher concentration (10\%) of the treatments.

Antifeedant activity of jatropha seed extracts against 14 days old larvae of $\boldsymbol{S}$ obliqua: The mean leaf area eaten by the 14 days old larvae of S. obliqua in jatropha seed extracts and cow urine treated and untreated castor leaves is given in table 3 . It has been noticed that after $24 \mathrm{hr}$. of exposure of larvae to the treated and untreated castor leaf area of $16.00 \mathrm{~cm}^{2}$, the leaf consumption was very less in castor discs treated with JSWE@10\%(5.38 cm $\left.\mathrm{cm}^{2}\right)$, and JSCUE@10\% $\left(6.12 \mathrm{~cm}^{2}\right)$ followed by other treatments of jatropha seed extracts and cow urine (range from $6.91 \mathrm{~cm} 2-12.05$ $\left.\mathrm{cm}^{2}\right)$ in comparison to control $\left(16.00 \mathrm{~cm}^{2}\right)$. After $48 \mathrm{hrs}$ of feeding on treated leaves it has been clearly noticed that the consumed leaf area was again reduced to $6.45 \mathrm{~cm}^{2}, 6.52 \mathrm{~cm}^{2}, 11.05 \mathrm{~cm}^{2}, 11.53 \mathrm{~cm}^{2}, 9.02 \mathrm{~cm}^{2}$, and $13.52 \mathrm{~cm}^{2}$ on JSWE @10\%, JSWE @5\%, CU @10\%, JSCUE@5\%,JSCUE@10\%, and CU@5\% treated castor leaf discs as compared to untreated control $\left(24.03 \mathrm{~cm}^{2}\right)$. After $72 \mathrm{hrs}$. of feeding on treated leaves relatively less leaf area was consumed by the larvae on JSWE@10\% (5.02 $\left.\mathrm{cm}^{2}\right)$ followed by JSWE @5\% $\left(7.51 \mathrm{~cm}^{2}\right)$ in comparison to leaf discs treated with JSCUE@10\% and CU@5\%(8.43 cm $\left.\mathrm{cm}^{2}-15.53 \mathrm{~cm}^{2}\right)$ significantly more leaf area consumed in untreated 
Table 2. Effect of jatropha seed extracts on growth and developmental behavior of 7 days old larvae of S. oblique.

\begin{tabular}{|c|c|c|c|c|c|c|c|}
\hline Treatment & Conc. & $\begin{array}{c}\text { larval } \\
\text { sur- } \\
\text { vival\% }\end{array}$ & $\begin{array}{l}\begin{array}{l}\text { Larval } \\
\text { period } \\
\text { (days) }\end{array} \\
\end{array}$ & $\begin{array}{c}\text { Pupation } \\
(\%)\end{array}$ & $\begin{array}{l}\text { Pupal } \\
\text { period } \\
\text { (days ) }\end{array}$ & $\begin{array}{c}\text { Adult emergence } \\
(\%)\end{array}$ & $\begin{array}{c}\text { Growth index } \\
\text { (G.I.) }\end{array}$ \\
\hline JSWE & 5 & $\begin{array}{c}33.33 \\
(35.26)\end{array}$ & $\begin{array}{l}13.33 \\
(21.42)\end{array}$ & $\begin{array}{l}24.08 \\
(16.65)\end{array}$ & $\begin{array}{l}18.46 \\
(10.02)\end{array}$ & $\begin{array}{c}21.43 \\
(13.35)\end{array}$ & 0.67 \\
\hline JSWE & 10 & $\begin{array}{l}16.65 \\
(24.08)\end{array}$ & $\begin{array}{c}6.00 \\
(11.21)\end{array}$ & $\begin{array}{c}0.00 \\
(0.00)\end{array}$ & $\begin{array}{c}0.00 \\
(0.00)\end{array}$ & $\begin{array}{c}0.00 \\
(0.00)\end{array}$ & 0.00 \\
\hline JSCUE & 5 & $\begin{array}{c}30.14 \\
(33.29)\end{array}$ & $\begin{array}{l}13.35 \\
(21.44)\end{array}$ & $\begin{array}{c}21.42 \\
(13.34)\end{array}$ & $\begin{array}{c}18.69 \\
(10.27)\end{array}$ & $\begin{array}{c}21.42 \\
(13.34)\end{array}$ & 0.66 \\
\hline JSCUE & 10 & $\begin{array}{l}26.65 \\
(24.08)\end{array}$ & $\begin{array}{c}11.82 \\
(18.34)\end{array}$ & $\begin{array}{l}0.00 \\
(0.00)\end{array}$ & $\begin{array}{l}0.00 \\
(0.00)\end{array}$ & $\begin{array}{l}0.00 \\
(0.00)\end{array}$ & 0.00 \\
\hline $\mathrm{CU}$ & 5 & $\begin{array}{c}50.24 \\
(45.14)\end{array}$ & $\begin{array}{l}16.65 \\
(24.08)\end{array}$ & $\begin{array}{c}39.35 \\
(40.20)\end{array}$ & $\begin{array}{c}18.91 \\
(10.50)\end{array}$ & $\begin{array}{c}35.27 \\
(33.34)\end{array}$ & 0.99 \\
\hline $\mathrm{CU}$ & 10 & $\begin{array}{c}47.27 \\
(39.39)\end{array}$ & $\begin{array}{l}16.22 \\
(27.16)\end{array}$ & $\begin{array}{c}35.28 \\
(33.35)\end{array}$ & $\begin{array}{c}18.99 \\
(10.60)\end{array}$ & $\begin{array}{c}31.09 \\
(26.68)\end{array}$ & 0.88 \\
\hline CONTROL & - & $\begin{array}{c}99.98 \\
(89.21)\end{array}$ & $\begin{array}{l}13.00 \\
(21.04)\end{array}$ & $\begin{array}{c}75.04 \\
(93.34)\end{array}$ & $\begin{array}{l}17.69 \\
(9.24)\end{array}$ & $\begin{array}{c}68.59 \\
(86.68)\end{array}$ & 2.23 \\
\hline SEm \pm & & $\begin{array}{c}0.08 \\
(0.07)\end{array}$ & $\begin{array}{c}0.00 \\
(0.00)\end{array}$ & $\begin{array}{c}0.02 \\
(0.05)\end{array}$ & $\begin{array}{c}0.08 \\
(0.08)\end{array}$ & $\begin{array}{c}0.00 \\
(0.01)\end{array}$ & \\
\hline CD $5 \%$ & & $\begin{array}{c}0.26 \\
(0.20)\end{array}$ & $\begin{array}{c}0.02 \\
(0.02)\end{array}$ & $\begin{array}{c}0.08 \\
(0.14)\end{array}$ & $\begin{array}{c}0.25 \\
(0.27)\end{array}$ & $\begin{array}{c}0.01 \\
(0.03)\end{array}$ & \\
\hline $\mathrm{CV}$ & & $\begin{array}{c}0.36 \\
(0.29)\end{array}$ & $\begin{array}{l}0.06) \\
(0.07)\end{array}$ & $\begin{array}{c}0.17 \\
(0.28)\end{array}$ & $\begin{array}{l}1.10 \\
(2.14)\end{array}$ & $\begin{array}{c}0.03 \\
(0.08)\end{array}$ & \\
\hline
\end{tabular}

Table 3. Mean leaf area consumed (MLAC) $\mathrm{cm}^{2}$ by 14 days old larvae of $S$. obliqua feeding on jatropha seed extracts treated leaf at different time intervals (leaf area provided $=16 \mathrm{~cm}^{2}$ ).

\begin{tabular}{lcccccc}
\hline Treatments & $\begin{array}{c}\text { Conc. } \\
(\boldsymbol{\%})\end{array}$ & \multicolumn{5}{c}{$\begin{array}{c}\text { MLAC } \mathbf{~ c m}^{2} \\
\text { Time interval (hours) }\end{array}$} \\
\cline { 2 - 6 } & & $\mathbf{2 4}$ & $\mathbf{4 8}$ & $\mathbf{7 2}$ & $\mathbf{9 6}$ & $\mathbf{1 2 0}$ \\
\hline JSWE & 5 & 6.91 & 6.52 & 7.51 & 3.32 & 2.15 \\
JSWE & 10 & 5.38 & 6.45 & 5.02 & 1.03 & 0.00 \\
JSCUE & 5 & 11.05 & 11.53 & 12.72 & 10.23 & 8.25 \\
JSCUE & 10 & 6.12 & 9.02 & 8.43 & 6.62 & 4.52 \\
CU & 5 & 12.05 & 13.52 & 15.53 & 13.24 & 10.24 \\
CU & 10 & 11.32 & 11.05 & 12.38 & 12.03 & 9.74 \\
CONTROL & & 16.03 & 24.03 & 31.74 & 38.52 & 24.54 \\
SEm \pm & & 0.05 & 0.02 & 0.01 & 0.01 & 0.01 \\
CD at 5\% & & 0.15 & 0.05 & 0.04 & 0.04 & 0.03 \\
CV & & 0.79 & 0.23 & 0.16 & 0.18 & 0.19 \\
\hline
\end{tabular}

control $\left(31.74 \mathrm{~cm}^{2}\right)$. After $96 \mathrm{hr}$ of feeding the mean leaf are eaten by larvae was again drastically reduced to JSWE@10\% ( $1.03 \mathrm{~cm}^{2}$ ) followed by JSWE @ 5\% $\left(3.32 \mathrm{~cm}^{2}\right)$, whereas in other treatments the mean leaf area eaten by the larvae ranged from $6.62 \mathrm{~cm}^{2}$ to $13.24 \mathrm{~cm}^{2}$ which were significantly less than untreated control $\left(38.52 \mathrm{~cm}^{2}\right)$. After $120 \mathrm{hrs}$ of feeding cent percent larval mortality was observed in castor leaves treated with JSWE@10\% less leaf area followed by JSWE $@ 5 \%(2.15 \mathrm{~cm} 2)$. Similarly the significant reduction in leaf consumption was also observed in other treatments i.e. JSCUE @5\% $\left(8.25 \mathrm{~cm}^{2}\right)$, CU $210 \%\left(9.74 \mathrm{~cm}^{2}\right)$ followed by CU @ $5 \%\left(10.24 \mathrm{~cm}^{2}\right)$ in comparison to untreated control $\left(24.54 \mathrm{~cm}^{2}\right)$.

The mean larval weight of 14 days old larvae of $S$. obliqua exposed to treated and untreated castor leaf discs at different time intervals are given in table 4 the data presented in Table-4 clearly showed the efficacy of different Jatropha seed extracts on larval weight of $S$ obliqua. At the start of the experiment the initial weight of the larvae was non significant different. After $24 \mathrm{hr}$ no any significant difference has been observed among the treatments but the significant difference was noticed after $48 \mathrm{hr}$ of feeding. The larval weight (298.27mg) was less in the treatments JSWE @10\% in comparison to other treatments treated leaf discs (range from $335.60 \mathrm{mg}-483.37 \mathrm{mg}$ ) in comparison to highest larval weight $(512.14 \mathrm{mg})$ in control. A continuous and significant reduction in larval weight was observed in treated castor leaf discs after 72 and $96 \mathrm{~h}$ of feeding. The reduction in larval weight in JSWE @ $10 \%$, JSCUE @10\% and CU @10\% was to the extent of 258.30, 315.57, 470.34mg respectively in contrast the larval weight $(619.27 \mathrm{mg})$ was considerably higher in 
Table 4. Mean larval weight $(\mathrm{mg})$ of 14 days old S. obliqua larvae after feeding on castor leaves treated with Cow urine and Jatropha seed extracts at different time intervals.

\begin{tabular}{|c|c|c|c|c|c|c|c|c|c|}
\hline \multirow[t]{2}{*}{ Treatment } & \multirow[t]{2}{*}{$\begin{array}{c}\text { Conc. } \\
(\%)\end{array}$} & \multirow{2}{*}{$\begin{array}{c}\text { Initial } \\
\text { wt. of } \\
\text { larvae } \\
(\mathrm{mg})\end{array}$} & \multicolumn{5}{|c|}{$\begin{array}{l}\text { Mean Larval weight (mg) } \\
\text { Time interval (hours) after }\end{array}$} & \multirow{2}{*}{$\begin{array}{c}\text { Mean } \\
\text { Pupal } \\
\text { wt. (mg) }\end{array}$} & \multirow{2}{*}{$\begin{array}{c}\text { Mean } \\
\text { ADULT } \\
\text { WEIGH }\end{array}$} \\
\hline & & & 24 & 48 & 72 & 96 & 120 & & \\
\hline JSWE & 5 & 235.14 & 291.37 & 361.27 & 378.34 & 382.34 & 412.34 & 152.32 & 82.34 \\
\hline JSWE & 10 & 235.37 & 266.10 & 298.27 & 258.30 & 201.20 & 163.44 & 0.00 & 0.000 \\
\hline JSCUE & 5 & 236.50 & 278.40 & 392.47 & 420.40 & 485.30 & 429.44 & 200.14 & 105.57 \\
\hline JSCUE & 10 & 234.47 & 301.30 & 335.60 & 315.57 & 374.50 & 246.34 & 133.02 & 92.27 \\
\hline $\mathrm{CU}$ & 5 & 234.30 & 315.20 & 410.24 & 498.34 & 515.27 & 500.24 & 212.24 & 118.37 \\
\hline $\mathrm{CU}$ & 10 & 233.27 & 295.50 & 483.37 & 470.34 & 592.37 & 420.34 & 198.47 & 96.50 \\
\hline CONTROL & & 234.87 & 365.34 & 512.14 & 619.27 & 659.27 & 789.37 & 342.50 & 238.17 \\
\hline SEm \pm & & 0.51 & 0.13 & 0.09 & 0.11 & 0.16 & 0.20 & 0.11 & 0.11 \\
\hline $\mathrm{CD}$ at $5 \%$ & & 1.52 & 0.38 & 0.28 & 0.35 & 0.50 & 0.62 & 0.34 & 0.34 \\
\hline CV & & 0.37 & 0.07 & 0.04 & 0.05 & 0.06 & 0.08 & 0.12 & 0.19 \\
\hline
\end{tabular}

Table 5. Comparative antifeedant activity of jatropha seed extracts against 14 days old larvae of $S$. obliqua (leaf area provided= $16 \mathrm{~cm}^{2}$ after 24 hrs of feeding.

\begin{tabular}{|c|c|c|c|c|c|}
\hline Treatments & Concentration (\%) & $\operatorname{MLAC}\left(\mathrm{cm}^{2}\right)$ & $\%$ Feeding & Feeding Inhibition (\%) & Preference index \\
\hline JSWE & 5 & 6.91 & 43.18 & 39.67 & 0.60 \\
\hline JSWE & 10 & 5.38 & 33.62 & 48.71 & 0.50 \\
\hline JSCUE & 5 & 11.05 & 69.06 & 18.29 & 0.81 \\
\hline JSCUE & 10 & 6.12 & 38.25 & 44.66 & 0.55 \\
\hline $\mathrm{CU}$ & 5 & 12.05 & 75.31 & 14.08 & 0.85 \\
\hline $\mathrm{CU}$ & 10 & 11.32 & 70.75 & 17.31 & 0.82 \\
\hline CONTROL & - & 16.00 & 100.0 & - & - \\
\hline
\end{tabular}

control experiments. It has been noticed that larval feeding on JSWE @ $10 \%$ treated leaves stopped after $72 \mathrm{hr}$ of feeding which resulted in reduction of larval weight and larval mortality. Consideration reduction in larval weight was also noticed in other treatments ranges (374.50 mg $-592 \mathrm{mg}$ ) in comparison to untreated control $(659.27 \mathrm{mg})$. After $96 \mathrm{hr}$ of exposure to treated castor leaves whereas some deformed pupae and adults were observed in jatropha seed extracts and cow urine treated castor leaf discs with mean pupal weight (133.0mg - 212.24 $\mathrm{mg}$ and mean adult weight (82.34mg - $118.37 \mathrm{mg}$ ) in comparison to control where weight of pupa and adult were $342.50 \mathrm{mg}$ and $238.17 \mathrm{mg}$, respectively.

It has been concluded from the above findings that due to antifeedant action in jatropha seed extract with water at $10 \%$ concentration, the larvae could not feed properly due to which their weight was reduced to such an extent that their mortality occurred whereas in the other treatments antifeedant action was mild so feeding was not much affected but larval and pupal growth affected by feeding on the growth disrupting.

The data given in table- 5 showed comparative antifeedant activity of jatropha seed extracts against 14 days old larvae of $S$. obliqua. A significantly less mean leaf area consumed by larvae in JSWE @10\% (5.38 $\left.\mathrm{cm}^{2}\right)$ followed by JSCUE @ $10 \%\left(6.12 \mathrm{~cm}^{2}\right)$, in comparison to other treatments where mean leaf area consumed were JSWE@5\% (6.91 cm²) CU @10\% (11.32cm2),
JSCUE @5 \% (11.05 cm²) and CU @5\% (12.05 cm²) significantly high mean leaf area consumed in untreated control $\left(16.00 \mathrm{~cm}^{2}\right)$. Similarly $\%$ feeding was calculated significantly less in JSWE @10\% (33.62) and JSCUE @10\% (38.25) in comparison to other treatments which were ranged from 43.18 to 75.31 . Per cent feeding inhibition was calculated significantly more in JSWE @10\% (48.71) followed by JSWE @5\% (39.67) with significantly less per cent feeding inhibition in JSCUE @ 10\% (44.66), CU @ 10\% (17.33), JSWE @5\% (39.67) and CU@5\% (14.08). similarly overall mean preference index indicated that none of the treatment were found to belong extremely Antifeedant category but the preference indices on jatropha seed extracts treated castor leaf discs were significantly less there for a strong antifeedant action was evidenced in JSWE@ $10 \%(0.50)$ and JSCUE@ $10 \%$ (0.55), whereas JSWE @ $5 \%$ (0.60) showed moderately antifeedant activity as compared to slightly antifeedant activity as observed in other treated castor leaf discs i.e CU @ $10 \%$, (0.82), JSCUE @ 5 \% (0.86), and CU @ $5 \%$ (0.88). It was also revealed from table 5 that in general the leaf area consumed at the higher concentration@10\% of different treatments were found promising than that of their lower concentration @ $5 \%$ of and therefore demonstrated high antifeedant activity.

Similar findings were also reported by Jing et al, (2004) that the efficacy of seed oil (extracted with 
ethanol) of Jatropha curcas having a contact toxicity on mustard aphid, Lipaphis erysimi. The seed oil showed strong contact toxicity with a $\mathrm{LD}_{50}$ of 2.1286 g/litre. Field experiments showed that the seed oil at $2.02 \mathrm{~g} /$ liter was highly effective in controlling the pest, and efficacy was maintained at $72.11 \%$ at 7 days after treatment.

Devanand and Usha Rani (2008) evaluated the antifeedant and toxic effects of leaf extracts of certain plant extracts, Murraya koenigii L., Jatropha curcas L., Tectona grandis L., Momordica charantia L., Mangifera indica L., Ricinus communis L., and the seed extract of Madhuca indica Gmelin., against the third instar larvae of two lepidopteron pests. Test extracts of $T$. grandis, $M$. indica and $M$. charantia produced higher toxicity ( $>80 \%$ ) to $S$. litura and $A$. janata at $20-100 \mathrm{mg} / 21 \mathrm{~cm}^{2} /$ larva doses were applied, and LD50 values of $\left(47.85-72.60 \mathrm{mg} / 21 \mathrm{~cm}^{2}\right)$. The other plants which were tested had moderate effects against these pests.

Chandel et al. (2009) reported the efficacy of Cabbage leaves (Brassica oleracea var. capitata) were treated with $2.0 \%$ of extracts of Adhatoda vasica [Justicia adhatoda], Alpinia galanga, Azadirachta indica, Curcuma domestica [Curcuma longa] and Cleome monophylla against Bihar hairy caterpillar (Spilarctia obliqua). All the botanical treatments were significantly superior to the untreated control.

Kumari and Chandla (2010) evaluated the effect of plant extracts, neem, J. curcas L., Chrysanthemum cinerariaefolium (Trev.), Eucalyptus globulus Labille, Vitex negundo L., and Urtica dioica L mixed with cow urine in 1: 9 parts and alone cow urine @ 0.5\% against B. coriacea. Cow urine alone was ineffective but the NSKE in urine resulted in no egg laying, minimum egg hatching (14-17\% versus $88-89 \%$ in control) and maximum mortality of first instar larvae (93-97\% versus $3-7 \%$ in control).

Tripathi et al. (2011) reported the deterrent and growth inhibitory activities of scopoletin isolated from Artemisia annua against Spilarctia obliqua (Lepidoptera: Noctuidae). Scopoletin gave $\mathrm{FD}_{50}$ (feeding deterrence of $50 \%$ ) value of $96.7 \mu \mathrm{g} / \mathrm{g}$ diet when mixed into artificial diet. S. obliqua larvae (12-day-old) exposed to the highest concentration $(250 \mu \mathrm{g} / \mathrm{g}$ diet $)$ of scopoletin showed $77.1 \%$ feeding-deterrence. In a growth inhibitory assay, scopoletin provided $116.9 \%$ growth inhibition at the highest dose of $250 \mu \mathrm{g} / \mathrm{g}$ diet with a $\mathrm{GI}_{50}$ (growth inhibition of $50 \%$ ) value of $20.9 \mu \mathrm{g} / \mathrm{g}$ diet

The use of plant and animal origin products in the field of agriculture for the insect pest management is an alternative and suitable novel approach all the country and the present studies revealed that the cow urine and cow urine based formulations can serve as a potential eco-friendly measures for management of $S$. obliqua.

\section{Conclusion}

This is the novel approach to study about the effect of animal origin product, cow urine alone and its decoctions prepared in Jatropha against growth and development of S. obliqua under laboratory conditions at Pantnagar. The present study revealed that the cow urine and cow urine based formulations can serve as a potential eco-friendly measure for management of lepidoteran insect $\mathrm{S}$ oblique and can be suitable alternatives to conventional chemical insecticides and are safe, readily available, almost free of cost to farmers and have long term effect without having any adverse effect on environment. Further studies are surely required to come to the final conclusions regarding the role of cow urine and its plant decoctions on the management of $S$. obliqua under field conditions.

\section{REFERENCES}

Chand, A. and Tiwari, R. (2010). Influence of cow urine and indigenous plant leaf extracts on feeding potential and larval weight of Spodoptera litura (Fabricius) (Noctuidae : Lepidoptera). Journal of insect science, 23: 313-317

Chandel, B.S. Vajpai, Rachna. Vajpai, Shail, Rajni (2009). Bio-efficacy of botanicals against Spilarctia oblique. Annals of Plant Protection Sciences. 17 (2) 465-466

Dubey, A. Gupta, R. and Chandel, B.S. (2004). Efficacy of Acorus calamus, Vitex negundo and Ageratum conyzoides against Tobacco caterpillar, Spilarctia obliqua (Walker). Indian Journal of Entomology. 66: 238-240

Gahukar, R.T. (2014). Potential and utilization of plant products in pest control. In: Abrol, D.P. (Ed.), Integrated Pest Management: Current Concepts and Ecological Perspective. Elsevier Inc, New York, NY, USA, pp. $125 \mathrm{e} 139$.

Garg, D.K. and Sachan S.K. (1992). Seasonal abundance of insect pests associated with soybean under hill conditions.Journal of Applied Zoological Research, 3(1):6870

Geetanjaly and Tiwari, R. (2013). Antifeedant and growth regulatory effects of neem leaf and jatropha seed extracts against Spodoptera litura (Fab.). J. Eco-friendly Agriculture. 8: 201-2003.

Gupta, M.P. (2005). Efficacy of neem in combination with cow urine against mustard aphid and its effect on coccinellid predators. Natural Product Radiance. 4: 102106.

Huang, H.S., Hu, N.T., Yao, Y.E., Wu, C.Y., Chiang, S.W. and Sun, C.N. (1998). Molecular cloning and heterologous expression of a glutathione $\mathrm{S}$ - transferase involved in insecticide resistance from the diamond back moth, Plutella xylostella. Insect Biochemistry and Molecular Biology, 28: 651-658.

Kogan, M. and Geodon, R.D. (1970). The host plant range of Lema trilineata daturaphila (Coleoptera: Chrysomelidae). Annals of Entomological Society America. 63: 1175-1180.

Kumari, N. and Chandla, V.K. (2010). Plant extracts in Cow urine (Bovine spp.): A new tool in the management of glasshouse whitefly, Trialeurodes vaporararium (Westwood). Journal of Ecofriendly Agriculture, 5(2): 154-155.

Li, Jing. Yan, Fang. Wu, FenHong. Yue, BiSong. Chen, Fang. (2004). Insecticidal activity of extracts from Jatropha curcas seed against Lipaphis erysimi. 
Acta Phytophylacica Sinica. 31 3: 289-293

Pande, Deepti and Srivastava, R.P. (2003). Toxicity and antifeedant activity of indoxacarb (Avaunt 14.5 SC) against tobacco caterpillar, Spodoptera litura (Fab.). Insect Environment, 9: 69-70.

Pant, N.C. (1956). Nutritional studies on Trogoderma granarium (Everts). Indian Journal of Entomology. 18: 259-266.

Patel, M.B. and Gajjar, S.N. (2001). Bioefficacy of various plant leaf extracts against Spodoptera litura (Fabricius) (Noctuidae: Lepidoptera). Indian Journal of Applied Entomology. 15: 32-34.

Panwar, S.S. and Chhibber, R.C. (2006). Influence of plant extract on feeding potential of Spilarctia obliqua. Indian Journal of Applied Entomology. 20: 22-24.

Peta, Devanand and Pathipati, Usha Rani (2008). Biological potency of certain plant extracts in management oftwo lepidopteran pests of Ricinus communis L. Journal of Biopesticides, 1(2): 170 - 176

Sadek, M.M. (2003). Antifeedant and toxic activity of Adhatoda vasica leaf extract against Spodoptera littoralis (Lepidoptera: Noctuidae). Journal Applied Entomology, 27: 396-404.
Sharma, R.K. and Bisht, R.S. (2008). Antifeedant activity of indigenous plant extracts against Spodoptera litura (Fabricius). Journal of Insect Science. 21: 56-60

Sharma, A.; Gupta, R. and Kanwar, R. (2009). Larvicidal effect of some plant extracts against Spodoptera litura (Fab.) and Pieris brassicae (Linn.) Journal of Entomological Research, 33: 213-218.

Singh, R.P. and Pant, N.C. (1980). Lycosine - A resistance factor in plants subfamily: Amarylloidiodae ( Amaryllidae) against desert locust. Experientia. 36: 552.

Singh, C.P., Pandey, M.C., Pant, A.K., Lackchaura, B.D. (1995). Antifeedant properties of some indigenous plant extract against Helicoverpa armigera. Bioved., 6: 17174.

Srivastava, K.P. (1993). A Text Book of Applied Entomology, Vol-II. Kalyani Pub. 266.

Tripathi, A.K. Singh Bhakuni, rajendra. Upadhyay, Sikha and Gaur, Rashmi. (2011). Insect feeding deterrent and growth inhibitory activities of scopoletin isolated from Artemisia annua against Spilarctia obliqua (Lepidoptera: Noctuidae) Insect Science, 18 (2):189 -194 . 